\title{
Leukocyte depletion attenuates expression of neutrophil adhesion molecules during cardiopulmonary bypass in human beings
}

\author{
Ying-Fu Chen, $\mathrm{MD}, \mathrm{PhD}^{\mathrm{a}}$ \\ Wen-Chan Tsai, MDC \\ Ching-Cheng Lin, $\mathrm{MD}^{\mathrm{b}}$ \\ Chee-Siong Lee, MD ${ }^{\mathrm{b}}$ \\ Chiung-Hui Huang, $\mathrm{BSc}^{\mathrm{a}}$ \\ Pi-Chen Pan, PhD ${ }^{\mathrm{d}}$ \\ Man-Lin Chen, $\mathrm{RN}^{\mathrm{a}}$ \\ Yeo-Shin Huang, MD, PhD
}

\footnotetext{
From the Divisions of Cardiovascular Surgery, ${ }^{\mathrm{a}}$ Cardiology, ${ }^{\mathrm{b}}$ and Immunology ${ }^{\mathrm{c}}$ and the Department of Public Health, Kaohsiung Medical University Hospital, Kaohsiung, Taiwan.

Supported by grants from the National Science Council of the Republic of China (NSC 88-2314-B-037-095).

Received for publication March 16, 2001; revisions requested May 14, 2001; revisions received July 25, 2001; accepted for publication July 26, 2001.

Address for reprints: Ying-Fu Chen, MD, $\mathrm{PhD}$, Division of Cardiovascular Surgery, Kaohsiung Medical University Hospital, 100 Shih-Chuan 1st Rd, Kaohsiung, Taiwan (Email: yfchen@cc.kmu.edu.tw).

J Thorac Cardiovasc Surg 2002;123:218-24

Copyright (C) 2002 by The American Association for Thoracic Surgery

0022-5223/2002 \$35.00+ $0 \quad \mathbf{1 2 / 1 / 1 1 9 0 6 5}$

doi:10.1067/mtc.2002.119065
}

\begin{abstract}
Background: On the basis of scanty information, the effects of a leukocyte filter during cardiac operations in human beings have been examined from the viewpoint of the expression of neutrophil adhesion molecules. This study was therefore designed to determine whether leukocyte depletion during cardiopulmonary bypass may interfere with neutrophil adhesion properties.
\end{abstract}

Methods: Twenty-four patients undergoing elective heart operations were randomly allocated to a leukocyte-depletion group or a control group. Blood samples were collected at 7 points: before sternotomy, at 10,30, and 60 minutes of cardiopulmonary bypass, at termination of cardiopulmonary bypass, 5 minutes after protamine administration, and 2 hours after cardiopulmonary bypass. The expression of the neutrophil surface adhesion molecules L-selectin and $\beta_{2}$-integrins was determined by flow cytometric analysis in whole blood.

Results: (1) CD11a expression did not change significantly in either group. There were no significant differences between control and leukocyte-depletion groups $(P$ $=.63$ ). (2) There was a significantly higher expression of CD11b on the neutrophils during cardiopulmonary bypass in the control group than in the leukocyte-depletion group $(P=.01)$. (3) $\mathrm{CD} 11 \mathrm{c}$ expression was initially up-regulated from the onset of cardiopulmonary bypass, reaching a peak at 60 minutes after bypass in the control group $(P=.02)$. The expression of CD11c did not differ significantly between groups $(P=.23)$. (4) L-selectin expression was significantly lower in the leukocytedepletion group than in the control group $(P=.03)$.

Conclusions: The major findings of the present study in human subjects undergoing elective cardiac operations with cardiopulmonary bypass are as follows: (1) bypass was associated with an up-regulation of the adhesion molecules L-selectin, CD11b, and CD11c but with no significant change in CD11a expression, and (2) the clinical use of a leukocyte-depleting filter could down-regulate the expression of CD11b and L-selectin.

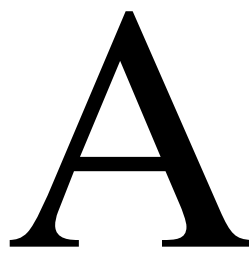

lthough technical refinements have improved the safety of cardiopulmonary bypass (CPB), patients can experience undesired effects, mainly attributed to a postperfusion general inflammatory response. A large body of evidence suggests that a portion of the morbidity associated with CPB can be attributed to the generalized inflammatory response caused by extracorporeal circula- 
tion. ${ }^{1}$ The main reason for this generalized inflammatory response is the contact of blood with foreign surfaces in components of the extracorporeal circulation apparatus. ${ }^{2}$ This response is largely mediated by the activation of polymorphonuclear leukocytes and by subsequent leukocyte deposition and interaction with the vascular endothelium. In recent years, the molecular mechanisms involved in this vital function of the immune system have been characterized. Specific cell adhesion molecules, which are expressed on the surface of neutrophils and mediate adhesive interaction, have been identified. The most important adhesion molecules expressed by neutrophils appear to be L-selectin and the $\beta_{2}$-integrins (CD11/CD18). The $\beta_{2}$-integrin (CD11/CD18) complex on the polymorphonuclear neutrophil consists of a constant $\beta$-chain (CD18) that is noncovalently linked to variable $\alpha$-units: CD11a, CD11b, and CD11c. The pairing of these $\alpha$-units with the constant $\beta$ unit leads to neutrophil cell surface expression of the CD11a/CD18 (leukocyte function-associated antigen-1), CD11b/CD18 (Mac-1 or $\mathrm{CR}_{3}$ ), and CD11c/CD18 (p150, 95, or $\mathrm{CR}_{4}$ ) receptor complex. ${ }^{3}$ Theoretically, reduction of the leukocyte population during CPB would result in decreased neutrophil-mediated tissue injury. Several recent studies demonstrated that leukocyte depletion in animal models ${ }^{4}$ or clinical use ${ }^{5}$ reduces heart and lung injury. Conflicting results have been noted, however, in other studies of clinical use of arterial line filters with leukocytedepleting capacity during $\mathrm{CPB}$, as assessed by the postoperative lung function parameters. ${ }^{6}$ On the basis of scanty information, the effects of leukocyte filters during cardiac operations in human beings have been examined from the viewpoint of the expression of neutrophil adhesion molecules. This study was therefore designed to determine whether leukocyte depletion during CPB may interfere with the neutrophil adhesion properties, thereby preventing the neutrophils from mediating widespread organ damage.

\section{Methods}

\section{Study Population}

Twenty-four patients electively undergoing coronary artery bypass grafting, heart valve replacement, or repair of a congenital heart defect were randomly allocated to a leukocyte-depletion (LD) group $(n=12)$ or a control group $(n=12)$. Exclusion criteria were infection, reoperation, and emergency operation. The demographic data of patients in both groups are summarized in Table 1. There was no significant difference in baseline characteristics between the 2 groups. All patients or their families gave informed consent before participating in this study.

\section{Conduction of CPB, Myocardial Protection, and Leukocyte Depletion}

The same standard anesthesia and CPB regimens were used in all patients. The heart was exposed through a median sternotomy, and sodium heparin at a dose of 300 units $/ \mathrm{kg}$ was administered intra-
TABLE 1. Patient demographic data*

\begin{tabular}{lccc}
\hline Variable & $\begin{array}{c}\text { Control } \\
(\mathbf{n = 1 2})\end{array}$ & $\begin{array}{c}\text { Depletion } \\
(\mathbf{n = 1 2})\end{array}$ & $\boldsymbol{P}$ value \\
\hline Age $(\mathrm{y})$ & $60 \pm 11$ & $60 \pm 14$ & $\mathrm{NS}$ \\
Sex & & & \\
$\quad$ Male & 10 & 11 & $\mathrm{NS}$ \\
$\quad$ Female & 2 & 1 & \\
Procedure & & & \\
$\quad$ Coronary artery bypass & 10 & 11 & NS \\
$\quad$ Valve replacement & 1 & 1 & \\
$\quad$ Heart defect repair & 1 & 0 & \\
No. of grafts & $3.0 \pm 0.9$ & $3.0 \pm 0.5$ & NS \\
CPB time (min) & $134 \pm 29$ & $138 \pm 23$ & NS \\
Aortic crossclamp time (min) & $97 \pm 20$ & $102 \pm 19$ & NS \\
Systemic hypothermia $\left({ }^{\circ} \mathrm{C}\right)$ & $28 \pm 1$ & $28 \pm 1$ & NS \\
\hline
\end{tabular}

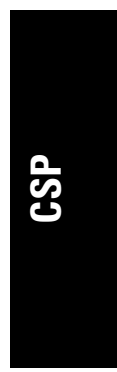

$C P B$, Cardiopulmonary bypass; $N S$, not significant

${ }^{*}$ Data are shown as mean \pm SD.

venously before $\mathrm{CPB}$ to produce an activated clotted time greater than 400 seconds. A disposable membrane oxygenator was used for CPB. The management of myocardial protection was identical in both groups. Cold intermittent blood cardioplegia resulting from mixing blood with high-potassium cardioplegic solution was administered in an antegrade fashion into the aortic root. Moderate systemic hypothermia was induced with the heat exchanger of the extracorporeal circuit. Topical cold saline solution or slush was used concomitantly. The leukocyte-depleting arterial blood filter for extracorporeal circulation (LeukoGuard-6; Pall Biomedical Product Corp, East Hillis, NY) was incorporated instead of a standard arterial filter in the circuit of 12 patients of the LD group.

\section{Blood Samples}

Blood samples were collected at 7 time points: (1) after induction of anesthesia but before sternotomy, (2-4) at 10, 30, and 60 minutes of CPB, (5) at the conclusion of CPB, (6) 5 minutes after the administration of protamine, and (7) 2 hours after the cessation of CPB. Samples were obtained from the arterial line before and after CPB. During CPB, samples were obtained from the arterial limb of the CPB circuit. Total white blood cell (WBC) and differential (neutrophil) counts were measured at these 7 time points by means of a blood cell counter (Cell-Dyn; Abbott Laboratories, Abbott Park, Ill) and expressed as the cell count $\times 10^{3} / \mathrm{mm}^{3}$.

\section{Flow Cytometric Analysis}

Expression of adhesion molecules was determined by directed 2color immunofluorescence staining of blood leukocytes and flow cytometry. Phycoerythrin (PE)-conjugated murine monoclonal antibodies directed against human adhesion molecules (CD11a, CD11c, L-selectin [purchased from Immunotech, Prague, Czech Republic], CD11b [purchased from BD Biosciences Pharmingen, San Diego, Calif] and immunoglobulin $G_{1}$ isotype control [purchased from Immunotech]) were used in combination with granulocyte-specific fluorescein isothiocyanate-conjugated CD16b (ID3; Immunotech). The mean CD4-PE fluorescence intensity determined by direct staining of lymphocytes by PE-conjugated 


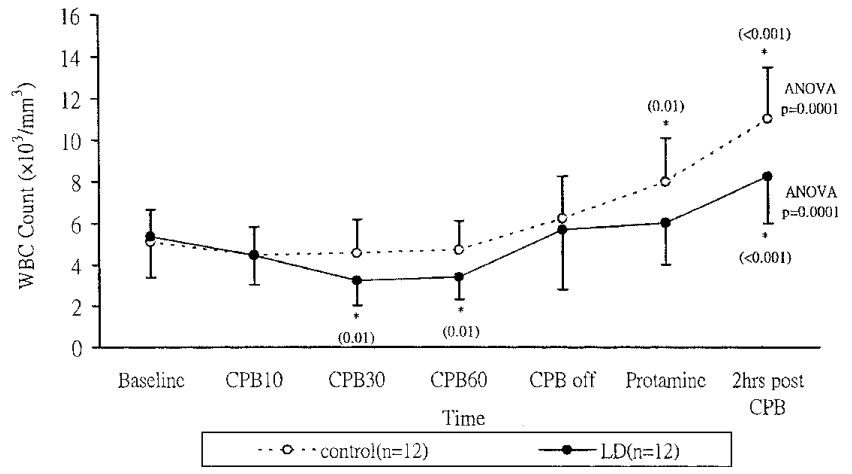

Figure 1. Total WBC counts before, during, and after CPB in the control group (open circles) and in the LD group (solid circles). * Significant difference compared with respective baseline, with $\boldsymbol{P}$ values shown in parentheses. Values are expressed as mean \pm SD. CPB10, CPB30, and CPB60, 10, 30, and 60 minutes after the start of cardiopulmonary bypass; WBC, white blood cell; $L D$, leukocyte depletion; ANOVA, analysis of variance.

CD4 (Pharmingen) was used as a biologic standard to estimate the molecules of adhesion molecules expressed on leukocytes. ${ }^{7}$

Blood leukocytes were prepared from freshly drawn heparinized blood. In brief, $1 \mathrm{~mL}$ of blood was immediately fixed for 4 minutes at $37^{\circ} \mathrm{C}$ with an equal volume of $0.4 \%$ formaldehyde in phosphate-buffered saline solution (PBS), $\mathrm{pH}$ 7.4. Red blood cells were then lysed for 5 minutes at $37^{\circ} \mathrm{C}$ with excess $(20 \mathrm{~mL})$ $0.83 \% \mathrm{NH}_{4} \mathrm{Cl}_{2}$ in $0.01 \mathrm{~mol} / \mathrm{L}$ Tris buffer. The leukocytes were pelleted at $300 \mathrm{~g}$ for 5 minutes, washed with ice-cold PBS solution, and resuspended in $0.5 \mathrm{~mL}$ RPMI 1640 culture medium (Gibco BRL, Life Technologies, Inc, Rockville, Md) containing glutamine $(2 \mathrm{mmol} / \mathrm{L})$, penicillin $(100 \mathrm{U} / \mathrm{mL})$, gentamicin $(40 \mathrm{mg} / \mathrm{mL})$, and $5 \%$ heat-inactivated fetal calf serum (Gibco).

For adhesion molecule labeling, 25- $\mu \mathrm{L}$ aliquots of leukocyte suspension were incubated 30 minutes on ice with a saturating concentration of murine monoclonal antibodies. After 3 washes in PBS solution, the cell pellets were resuspended in a $1 \%$ solution of formaldehyde in PBS. Samples were then kept at $4^{\circ} \mathrm{C}$ in the dark until analysis.

Flow cytometric analysis of cellular fluorescence was performed on an EPICS Elite ESP cytometer (Coulter Corporation, Hialeah, Fla). Ten thousand events were acquired from each sample. Neutrophils were gated on the basis of their forward and orthogonal light scatter and then on the CD16b positivity. Cursors were then set to measure the mean relative fluorescence intensity (RFI) of the population under study. The calculation of the number of PE-bound adhesive molecules expressed on the granulocyte was based on the following equation: (Anti-adhesion molecule - PE RFI - Immunoglobulin $\mathrm{G}_{1}-\mathrm{PE}$ RFI) $\times 50,000 / \mathrm{CD} 4-\mathrm{PE}$ RFI. The values were then expressed as a percentage of the baseline value.

\section{Statistical Analysis}

All values are expressed as the mean \pm SD. Comparisons between groups were made by means of 2-way analysis of variance for repeated measurements. Comparisons within groups were per-

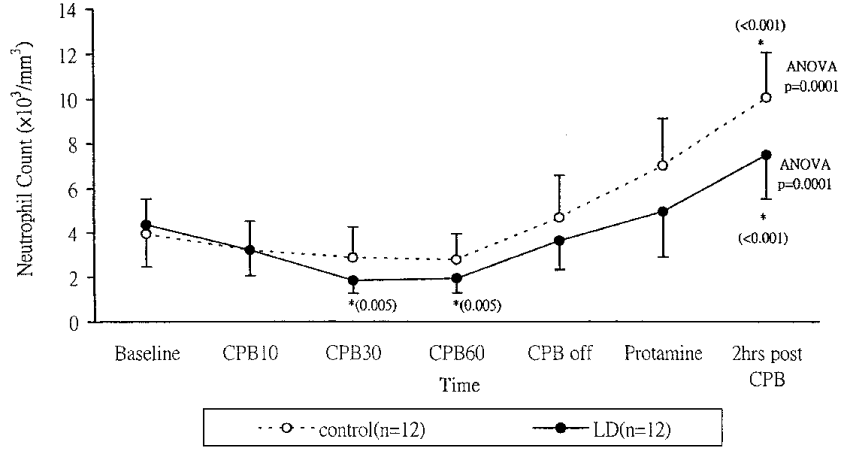

Figure 2. Total neutrophil counts before, during, and after CPB in the control group (open circles) and in the LD group (solid circles). *Significant difference compared with respective baseline, with $\boldsymbol{P}$ values shown in parentheses. Values are expressed as mean \pm SD. CPB10, CPB30, and CPB60, 10, 30, and 60 minutes after the start of cardiopulmonary bypass; WBC, white blood cell; $L D$, leukocyte depletion; ANOVA, analysis of variance.

formed by means of 1-way analysis of variance followed by the Tukey test for multiple comparisons.

\section{Results}

\section{Blood Cell Counts}

Before $\mathrm{CPB}$, the total $\mathrm{WBC}$ counts were similar in both groups $\left(5.1 \pm 1.5 \times 10^{3}\right.$ cells $/ \mathrm{mm}^{3}$ in the control group vs $5.4 \pm 1.9 \times 10^{3}$ cells $/ \mathrm{mm}^{3}$ in the LD group; $P=.74$, Figure $1)$. In the control group, no significant change in the total WBC count during CPB was followed by significant leukocytosis in the period after CPB $\left(5.1 \pm 1.5 \times 10^{3}\right.$ cells $/ \mathrm{mm}^{3}$ before $\mathrm{CPB}$ vs $11.1 \pm 2.3 \times 10^{3}$ cells $/ \mathrm{mm}^{3} 2$ hours after CPB; $P<.001$, Figure 1). On the contrary, a significant decrease in the total WBC count during CPB was noted in the LD group $\left(5.4 \pm 1.9 \times 10^{3}\right.$ cells $/ \mathrm{mm}^{3}$ before $\mathrm{CPB}$ vs 3.2 $\pm 1.2 \times 10^{3}$ cells $/ \mathrm{mm}^{3}$ at 30 minutes of $\mathrm{CPB} ; P=.01$ ), although significant leukocytosis was also noted 2 hours after CPB $\left(5.4 \pm 1.9 \times 10^{3}\right.$ cells $/ \mathrm{mm}^{3}$ before CPB vs $8.4 \pm$ $2.3 \times 10^{3}$ cells $/ \mathrm{mm}^{3} 2$ hours after $\left.\mathrm{CPB} ; P<.001\right)$. Analysis of the neutrophil counts revealed a pattern similar to those described by the total WBC counts (Figure 2). After CPB, the neutrophil counts increased significantly compared with counts before $\mathrm{CPB}$ in both groups $\left(4.0 \pm 1.5 \times 10^{3}\right.$ cells $/ \mathrm{mm}^{3}$ before CPB vs $10.1 \pm 2.3 \times 10^{3}$ cells $/ \mathrm{mm}^{3} 2$ hours after CPB for the control group; $P<.001$; and $4.4 \pm$ $1.8 \times 10^{3}$ cells $/ \mathrm{mm}^{3}$ before CPB vs $7.5 \pm 1.9 \times 10^{3}$ cells $/ \mathrm{mm}^{3} 2$ hours after CPB for the LD group; $P<.001$ ). The efficacy of leukocyte depletion during CPB was significant in the LD group $\left(4.4 \pm 1.8 \times 10^{3}\right.$ cells $/ \mathrm{mm}^{3}$ before $\mathrm{CPB}$ vs $1.8 \pm 0.6 \times 10^{3}$ cells $/ \mathrm{mm}^{3}$ at 30 minutes of $\mathrm{CPB} ; P$ $=.005)$. However, there were no significant changes in neutrophil counts during $\mathrm{CPB}$ in the control group $(4.0 \pm 1.5 \times$ 


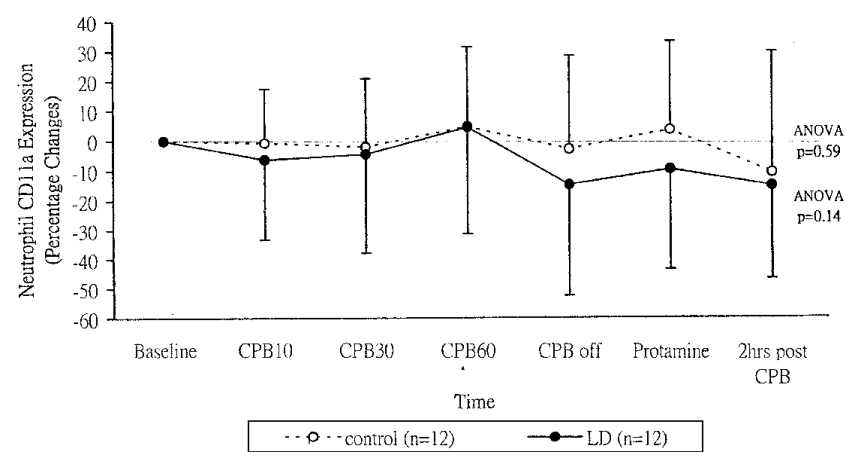

Figure 3. Time course of neutrophil CD11a expression during and after CPB in the control group (open circles) and in the LD group (solid circles). There is no significant difference between control and LD groups ( $P=.63$ by ANOVA). Values are expressed as mean \pm SD. CPB10, CPB30, and CPB60, 10, 30, and 60 minutes after the start of cardiopulmonary bypass; WBC, white blood cell; $L D$, leukocyte depletion; ANOVA, analysis of variance.

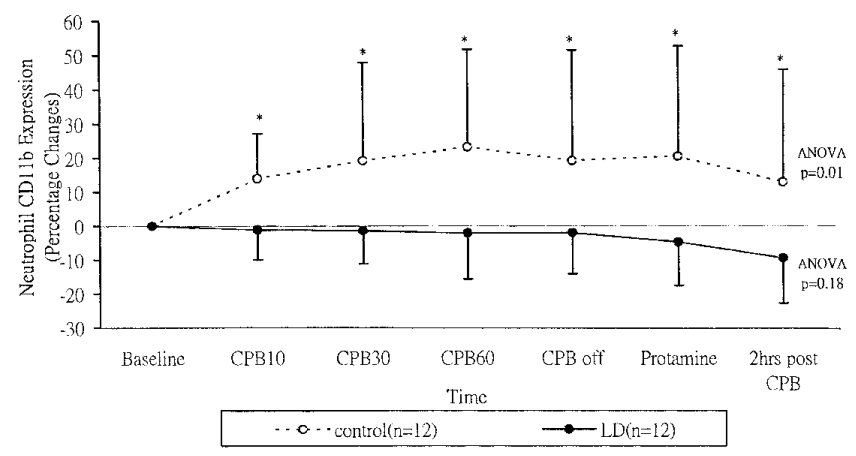

Figure 4. Time course of neutrophil CD11b expression during and after CPB in the control group (open circles) and in the LD group (solid circles). There is a significant difference between control and LD groups $\left(P=.01\right.$ by ANOVA). ${ }^{*}<.001$ compared with the LD group. Values are expressed as mean \pm SD. CPB10, CPB30, and $C P B 60,10,30$, and 60 minutes after the start of cardiopulmonary bypass; WBC, white blood cell; $L D$, leukocyte depletion; ANOVA, analysis of variance.

$10^{3}$ cells $/ \mathrm{mm}^{3}$ before CPB vs $2.9 \pm 1.3 \times 10^{3}$ cells $/ \mathrm{mm}^{3}$ at 30 minutes of $\mathrm{CPB} ; P=.2$ ).

\section{CD11a}

Figure 3 depicts neutrophil cell surface CD11a expression in the control and LD groups. CD11a expression did not change significantly from the baseline presternotomy values in either group over the observation period. There were no significant differences between the control group and the LD group $(P=.63)$.

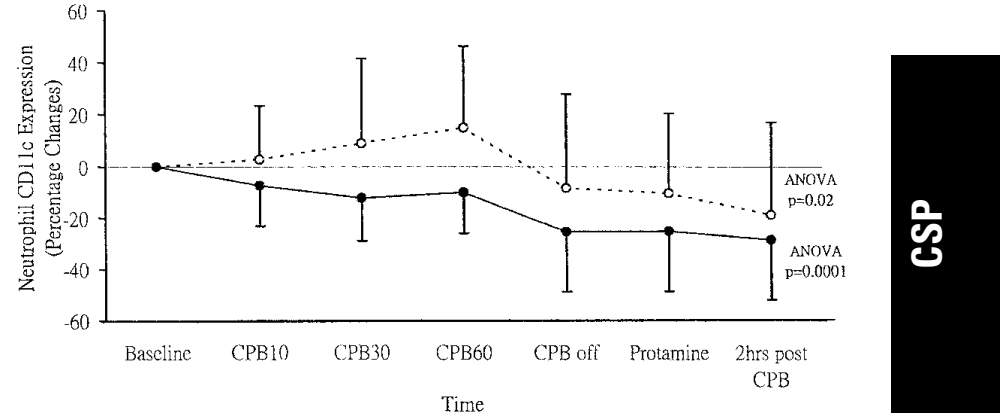

Figure 5. Time course of neutrophil CD11c expression during and after CPB in the control group (open circles) and in the LD group (solid circles). There is no significant difference between control and LD groups ( $P=.23$ by ANOVA). Values are expressed as mean \pm SD. CPB10, CPB30, and CPB60, 10, 30, and 60 minutes after the start of cardiopulmonary bypass; $W B C$, white blood cell; $L D$, leukocyte depletion; ANOVA, analysis of variance.

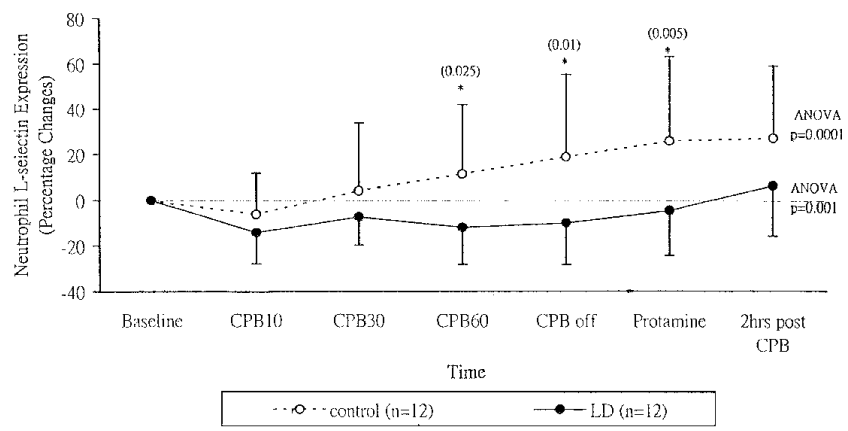

Figure 6. Time course of neutrophil L-selectin expression during and after CPB in the control group (open circles) and in the LD group (solid circles). There is a significant difference between control and LD groups ( $P=.03$ by ANOVA). *Significant difference compared with the LD group, with $P$ values in parentheses. Values are expressed as mean $\pm S D$. CPB10, CPB30, and CPB60,10,30, and 60 minutes after the start of cardiopulmonary bypass; WBC, white blood cell; $L D$, leukocyte depletion; ANOVA, analysis of variance.

\section{CD11b}

The time course of neutrophil CD11b expression during and after CPB in both groups is illustrated in Figure 4. In the control group, CD11b expression showed a sharp increase and a statistically significant difference $(P=.01)$. Conversely, CD11b expression during CPB was not statistically significant $(P=.18)$ in the LD group. There was a significantly higher expression of CD11b on the neutrophils during CPB in the control group compared with the LD group $(P=.01)$. 


\section{CD11c}

CD11c expression was initially up-regulated from the onset of $\mathrm{CPB}$, reaching a peak at 60 minutes after $\mathrm{CPB}$ in the control group. Thereafter, a drop of CD11c expression was observed $(P=.02)$ (Figure 5). Interestingly, the expression of CD11c decreased significantly during and after CPB in the LD group $(P=.0001)$. However, this decrease of CD11c expression did not differ significantly between groups $(P=.23)$.

\section{L-selectin}

Figure 6 shows the time course of neutrophil L-selectin expression during and after CPB in both groups. CPB was associated with a rapid and statistically significant increase of L-selectin in the control group $(P=.0001)$. On the contrary, down-regulation of neutrophil L-selectin was observed in the LD group $(P=.001)$. The L-selectin expression was significantly lower in the LD group than in the control group during and after bypass $(P=.03)$

\section{Discussion}

\section{Total WBC and Neutrophil Counts}

In the present study, total WBC and neutrophil counts did not change significantly during CPB in the control group. However, the number of circulating total WBCs and neutrophils decreased markedly during the $\mathrm{CPB}$ period in the LD group. Animal ${ }^{4}$ and clinical $^{5}$ studies also supported these findings. As is known, CPB activates complement factors, inducing the activation of neutrophils, which is believed to be primarily responsible for CPB-related inflammatory response. ${ }^{1}$ Because the activated neutrophils are more likely to be trapped by a leukocyte filter, it is probable that very few activated neutrophils escaped filtration. ${ }^{8}$

\section{Patterns of CPB With or Without Leukocyte Filtration on Neutrophil Adhesion Molecules}

The 2 major findings of the present study in human subjects undergoing elective cardiac operations with $\mathrm{CPB}$ are that (1) CPB was associated with an up-regulation of the adhesion molecules L-selectin, CD11b, and CD11c, but no significant change in CD11a expression, and (2) the clinical use of a leukocyte-depleting filter could down-regulate the expression of CD11b and L-selectin.

Numerous experimental and clinical studies have demonstrated that activated neutrophils are key mediators of the systemic inflammatory response. ${ }^{1,9}$ The activated neutrophils may interact with similarly activated endothelium, resulting in enhanced neutrophil-endothelial cell adhesion and neutrophil sequestration. Increasing evidence indicates that leukocyte-endothelial cell interactions are regulated by a cascade of molecular steps that correspond to the morphologic changes and accompany adhesion. ${ }^{10}$ This adhesion sequentially involves 2 classes of neutrophil cell-surface receptors. The first stage of the adhesion process involves L- selectin. L-selectin is responsible for leukocyte rolling and is rapidly shed on chemotactic stimulation. Subsequent firm adhesion to activated endothelium is mediated by upregulation of the $\beta_{2}$-integrin. ${ }^{3}$ By this binding, a complex pathophysiologic process is activated, which results in marked microvascular injury and thus tissue damage.

\section{L-selectin}

The rolling of neutrophils on the endothelium appears to be a prerequisite for eventual adherence to blood vessels under conditions of flow, ${ }^{11}$ and this is mediated by members of the selectin family. The adhesive interaction is spatially specific, occurring in vessels-primarily postcapillary venules. ${ }^{12}$ L-selectin, which is constitutively expressed on unactivated neutrophils, is a transmembrane protein present on the surface of the resting neutrophils that participates in the process of rolling. The membrane proximal region of $\mathrm{L}$ selectin contains a site that is susceptible to endoproteolytic cleavage by an endogenous membrane-bound protease after cell activation. ${ }^{13}$ The cleavage product is functionally active and is present at high levels in normal serum, where it may down-regulate inflammatory responses. ${ }^{14}$ The importance of the neutrophil L-selectin in the initial rolling of neutrophils on endothelium was supported by a number of studies. Monoclonal antibody blockade of L-selectin function has proven to be an effective method of reducing neutrophil rolling both in vitro ${ }^{15}$ and in vivo. ${ }^{3}$ Our study has demonstrated that neutrophil surface expression of L-selectin was shown to increase in the control group during CPB $(P=$ $.0001)$. McBride and coworkers ${ }^{16}$ similarly reported an increase in neutrophil L-selectin expression during CPB. Whether L-selectin expression on neutrophils is up-regulated during human CPB is controversial, because some investigators have reported a decrease in expression ${ }^{17}$ but others have found no change. ${ }^{18}$ The reason for the discrepancy in these results is unknown. Interestingly, a significant down-regulation of L-selectin expression could be found in the LD group during CPB $(P=.001)$ in our study. Moreover, the use of a leukocyte filter significantly reduced the expression of L-selectin during CPB in the LD group compared with the control group $(P=.03)$. This finding may have implications for the clinical use of leukocyte filters, which may induce L-selectin shedding.

\section{Expression of CD11a}

Our data demonstrate that CD11a expression did not change significantly from the baseline values in either group over the observation period. Similarly, the observation that CD11a expression did not change significantly during or after $\mathrm{CPB}$ has been reported previously in simulated $\mathrm{CPB}^{19}$ or actual CPB. ${ }^{18,20}$ Because CD11a is involved primarily in the adhesion of lymphocytes, as evidenced by the efficacy of anti-leukocyte function-associated antigen-1 mono- 
clonal antibodies, it has been used to prevent graft failure. ${ }^{21}$ CD11 a plays a limited role in the adhesion of activated neutrophils. This was further supported by the previous observation that anti-CD11a monoclonal antibodies were unable to block neutrophil adhesion. ${ }^{22}$ In addition, the leukocytedepleting filter is associated with a depletion of neutrophils during the CPB period and with preservation of lymphocytes. $^{23}$ Therefore, no significant difference of CD11a expression would be expected between the control group and the LD group $(P=.63)$, as in our study.

\section{Expression of CD11c}

CD11c reacts with different ligands, in particular the complement cleavage product iC $3 b .^{24}$ The contributions of $\mathrm{CD} 11 \mathrm{c}$ to $\mathrm{iC} 3 \mathrm{~b}$ binding by neutrophils and monocytes have been demonstrated by Myones and associates. ${ }^{25}$ This iC3breceptor activity of CD11c was previously designated $\mathrm{CR}_{4} \cdot{ }^{26}$ The CD11c integrin exhibits some binding activity of CD11b. Myones and associates ${ }^{25}$ suggested that CD11b and $\mathrm{CD} 11 \mathrm{c}$ have common functions in mediating neutrophil and monocyte adherence to endothelial cells. Typically, antibodies against CD11c are much less potent in inhibiting leukocyte adhesion than anti-CD11b monoclonal antibodies. ${ }^{25}$ Therefore, the CD11b integrin is the most important membrane glycoprotein of $\beta_{2}$-integrin family for neutrophil-endothelial cell adherence. Nevertheless, the CD11c glycoprotein is a major adhesion-associated molecule expressed by human monocytes. ${ }^{27}$ Our findings indicated that $\mathrm{CD} 11 \mathrm{c}$ continued to up-regulate during $\mathrm{CPB}$, reaching a peak 60 minutes after the onset of $\mathrm{CPB}$, and then a drop of CD11c expression was observed in the control group. Similar increases in CD11c expression on neutrophils during CPB have been reported in the majority of studies, ${ }^{18}$ although it remained unchanged ${ }^{20}$ or even decreased ${ }^{17}$ in other studies. Our studies demonstrated that the use of a leukocyte filter significantly reduced the expression of CD11c during and after CPB. However, the change in CD11c expression did not reach statistical significance between groups.

\section{Expression of CD11b}

In unstimulated neutrophils, CD11b is present in intracellular, vesicular compartments, as well as on the cell surface. ${ }^{28}$ During CPB, neutrophils may be activated by several stimuli, including direct contact with synthetic surface, ${ }^{2}$ complement-derived anaphylatoxin, platelet-activating factor, kallikrein, leukotriene, and interleukin 8. ${ }^{29}$ Expression of CD11b can be increased rapidly (in seconds) and dramatically (a 3- to 10-fold increase) on the surface of neutrophils through translocation of intracellular stores to the cell surface after exposure to the above stimuli. ${ }^{30}$ In addition, neutrophil exposure to chemoattractant stimuli causes not only increased surface expression of CD11b but also conforma- tional changes in the molecule that increase its adhesiveness. ${ }^{30}$ The resulting neutrophil adherence to vascular endothelium is a crucial early step in neutrophil-mediated endothelial injury. This adhesion of neutrophils via CD11b primes the neutrophil to degranulate and to produce oxygen-derived free radicals via the respiratory burst. ${ }^{31}$ Neutrophil-mediated tissue damage is further amplified as a transendothelial cell chemotactic gradient (largely driven by interleukin $8^{32}$ ) makes adherent neutrophils detach and migrate into the interstitium, where they can injure parenchymal cell directly. In animal models of ischemiareperfusion, administration of antibodies to $\mathrm{CD} 11 \mathrm{~b}$ has reduced end-organ damage in the lung, heart, and skeletal muscle. ${ }^{33}$ Our findings of marked up-regulation of CD11b during $\mathrm{CPB}$ in the control groups support similar findings in the majority of studies, ${ }^{16,17,20}$ although CD11b decreased in other studies. ${ }^{34}$ On the other hand, the use of a leukocyte filter significantly reduced the expression of CD11b during $\mathrm{CPB}$, an effect that lasted up to 2 hours after the end of CPB. Several trials have already tested the efficacy of technique $^{17,18}$ and pharmacologic agents ${ }^{20}$ that inhibit inflammatory response during CPB. Of these, hypothermia has been widely used for clinical CPB to attenuate the expression of neutrophil integrin CD11b. However, hypothermia was unable to prevent a postbypass increase in the expression of CD11b. ${ }^{18}$ On the contrary, the use of a leukocyte filter continued to reduce $\mathrm{CD} 11 \mathrm{~b}$ expression up to 2 hours after the cessation of CPB, as our studies demonstrated.

\section{Clinical Implication}

Many experimental and clinical studies have demonstrated that CPB leads to a systemic inflammatory response, with leukocytes playing a key role in the inflammatory process. Leukocyte depletion from the systemic circulation during CPB has been reported to reduce free radical-mediated lung injury and neutrophil-mediated ventricular dysfunction in animal experiments ${ }^{4}$ and patients. ${ }^{5}$ Our studies show downregulation of L-selectin and CD11b in the LD group compared with the control group. This down-regulation was probably due to the retention of most of the activated leukocytes by the leukocyte filter. ${ }^{8}$ If down-regulation of Lselectin and CD11b implies a concomitant decrease in the adhesive and migratory properties of neutrophils, one may conclude that the use of a leukocyte filter in patients undergoing cardiac surgery might ameliorate the CPB-induced inflammatory response: (1) by reducing the population of neutrophils and (2) by reducing the state of activation of the neutrophils because of the down-regulation of L-selectin and CD11b on neutrophils.

\section{References}

1. Edmunds LH Jr. Inflammatory response to cardiopulmonary bypass. Ann Thorac Surg. 1998;66:S12-6. 
2. El Habbal MH, Smith LJ, Elliott MJ, Strobel S. Cardiopulmonary bypass tubes and prime solutions stimulate neutrophil adhesion molecules. Cardiovasc Res. 1997;33:209-15.

3. von Andrian UH, Chambers JD, McEvoy LM, Bargatze RF, Arfors KE, Butcher EC. Two-step model of leukocyte-endothelial cell interaction in inflammation: distinct roles for LECAM-1 and the leukocyte $\beta_{2}$ integrin in vivo. Proc Natl Acad Sci U S A. 1991;88:7538-42.

4. Wilson IC, Gardner TJ, DiNatale JM, Gillinov AM, Curtis WE, Cameron DE. Temporary leukocyte depletion reduces ventricular dysfunction during prolonged postischemic reperfusion. J Thorac Cardiovasc Surg. 1993;106:805-10.

5. Morioka K, Muraoka R, Chiba Y, Ihaya A, Kimura T, Noguti H, et al. Leukocyte and platelet depletion with a blood cell separator: effects on lung injury after cardiac surgery with cardiopulmonary bypass. $J$ Thorac Cardiovasc Surg. 1996;111:45-54.

6. Mihaljevic T, Tonz M, von Segesser LK, Pasic M, Grob P, Fehr J, et al. The influence of leukocyte filtration during cardiopulmonary bypass on postoperative lung function: a clinical study. $J$ Thorac Cardiovasc Surg. 1995;109:1138-45.

7. Hultin LE, Matud JL, Giorgi JV. Quantitation of CD38 activation antigen expression of CD8+ T cells in HIV-1 infection using CD4 expression on CD4+ T lymphocytes as a biological calibrator. Cytometry. 1998;33:123-32.

8. Bolling KS, Halldorsson A, Allen BS, Rahman S, Wang T, Kronon M, et al. Prevention of the hypoxic reoxygenation injury with the use of a leukocyte-depleting filter. J Thorac Cardiovasc Surg. 1997;113: 1081-90.

9. Elliott MJ, Finn AHR. Interaction between neutrophils and endothelium. Ann Thorac Surg. 1993;56:1503-8.

10. Butcher EC. Leukocyte-endothelial cell recognition: three (or more) steps to specificity and diversity. Cell. 1991;67:1033-6.

11. von Andrian UH, Hansell P, Chamber JD, Filho IT, Butcher EC, Arfors KE. L-selectin function is required for $\beta_{2}$ integrin-mediated adhesion at physiological shear rates in vivo. Am J Physiol. 1992;263: H1034-44.

12. Albelda SM, Smith CW, Ward PA. Adhesions molecules and inflammatory injury. FASEB J. 1994;8:504-12.

13. Chen A, Engel P, Tedder TF. Structural requirements regulate endoproteolytic release of the L-selectin $(\mathrm{CD} 62 \mathrm{~L})$ adhesion receptor from the cell surface of leukocytes. J Exp Med. 1995;182:519-30.

14. Schleiffenbaum BE, Spertini O, Tedder TF. Soluble L-selectin is present in human plasma at high levels and retains functional activity. $J$ Cell Biol. 1992;119:229-38.

15. Smith CW, Kishimoto TK, Abbass O, Hughes B, Rothlein R, McIntire $\mathrm{LV}$, et al. Chemotactic factors regulate lectin adhesion molecule 1 (LECAM-1)-dependent neutrophil adhesion to cytokine-stimulated endothelial cells in vitro. J Clin Invest. 1991;87:609-18.

16. McBride WT, Armstrong MA, Crockard AD, McMurray TJ, Rea JM Cytokine balance and immunosuppressive changes at cardiac surgery: contrasting response between patients and isolated CPB circuits. $\mathrm{Br} \mathrm{J}$ Anaesth. 1995;75:724-33.

17. Moen O, Hogasen K, Fosse E, Dregelid E, Brockmeier V, Venge P, et al. Attenuation of changes in leukocyte surface markers and complement activation with heparin-coated cardiopulmonary bypass. Ann Thorac Surg. 1997;63:105-11.

18. Deist FL, Menasche P, Kucharski C, Bel A, Piwnica A, Bloch G. Hypothermia during cardiopulmonary bypass delays but does not pre- vent neutrophil-endothelial cell adhesion: a clinical study. Circulation. 1995;92(Suppl):II354-8.

19. Finn A, Morgan BP, Rebuck N, Klein N, Rogers CA, Hibbs M, et al. Effects of inhibition of complement activation using recombinant soluble complement receptor 1 on neutrophil CD11b/CD18 and Lselectin expression and release of interleukin-8 and elastase in simulated cardiopulmonary bypass. J Thorac Cardiovasc Surg. 1996; 111:451-9.

20. Hill GE, Alonso A, Thiele GM, Robbins RA. Glucocorticoids blunt neutrophil CD11b surface glycoprotein upregulation during cardiopulmonary bypass in humans. Anesth Analg. 1994;79:23-7.

21. Fisher A, Griscelli C, Blanche S, Le Deist F, Veber F, Lopez M, et al. Prevention of graft failure by an anti-HLA-1 monoclonal antibody in HLA-mismatched bone marrow transplantation. Lancet. 1986;2:105861.

22. Lefer DJ, Shandelya SML, Serrano CV, Becker LC, Kuppusamy P, Zwier JL. Cardioprotective actions of a monoclonal antibody against CD-18 in myocardial ischemia-reperfusion injury. Circulation. 1993;88:1779-87.

23. Gourlay T, Fleming J, Taylor KM. Laboratory evaluation of the Pall LG6 leukocyte depleting arterial line filter. Perfusion. 1992;7:131-40.

24. Hogg N. The leukocyte integrins. Immunol Today. 1989;10:111-4.

25. Myones BL, Dalzell JG, Hogg N, Ross GD. Neutrophil and monocyte cell surface p150,95 has iC3b-receptor (CR4) activity resembling CR3. J Clin Invest. 1988;82:640-51.

26. Frade R, Myones BL, Barel M, Krikorian L, Charriaut C, Ross GD. GP 140, a C3b-binding membrane component of lymphocytes, is the $\mathrm{B}$ cell $\mathrm{C} 3 \mathrm{dg} / \mathrm{C} 3 \mathrm{~d}$ receptor $\left(\mathrm{CR}_{2}\right)$ and is distinct from the neutrophil C3dg receptor $\left(\mathrm{CR}_{4}\right)$. Eur J Immunol. 1985;15:1192-7.

27. Keizer GD, Te Velde AA, Schwarting R, Figdor CG, DeVries JE. Role of p150,95 in adhesion, migration, chemotaxis and phagocytosis of human monocyte. Eur J Immunol. 1987;17:1317-22.

28. Borregaard N, Miller LJ, Springer TA. Chemoattractant-regulated fusion of a novel mobilizable intracellular compartment with the plasma membrane in human neutrophils. Science. 1987;237:1204-6.

29. Detmers PA, Lo SK, Olsen Egbert E, Walz A, Baggiolini M, Cohn ZA. Neutrophil-activating protein 1 /interleukin-8 stimulates the binding activity of the leukocyte adhesion receptor CD11b/CD18 on human neutrophils. J Exp Med. 1990;171:1155-62.

30. Smith CW, Marlin SD, Rothlein R, Toman C, Anderson DC. Cooperative interactions of LFA-1 and Mac-1 with intercellular adhesion molecule-1 in facilitating adhesion and transendothelial migration of human neutrophils in vitro. J Clin Invest. 1989;83:2008-17.

31. Shappell SB, Toman C, Anderson DC, Taylor AA, Entman ML, Smith CW. Mac-1 (CD11b/CD18) mediates adherence-dependent hydrogen peroxide production by human and canine neutrophils. J Immunol. 1990;144:2702-11.

32. Huber AR, Kunkel SL, Todd RF, Weiss SJ. Regulation of transendothelial neutrophil migration by endogenous interleukin-8. Science. 1991;254:99-102.

33. Simpson PJ, Todd RF III, Fantone JC, Mickelson JK, Griffin JD, Lucchesi BR, et al. Reduction of experimental canine myocardial reperfusion injury by a monoclonal antibody (anti-Mol, anti-CD11b) that inhibits leukocyte adhesion. J Clin Invest. 1988;81:624-9.

34. Galiñanes M, Watson C, Trivedi U, Chambers DJ, Young CP, Venn GE. Differential patterns of neutrophil adhesion molecules during cardiopulmonary bypass in humans. Circulation. 1996;94(Suppl):II-364-9. 